\title{
Single Stage High Frequency LC Resonant Inverter
}

\author{
R. Venugopal, M.E. \\ Assistant professor, \\ Anna University, Chennai \\ Dhanalakshmi College \\ Engineering, Chennai.
}

\author{
D. Mohan, M.E. \\ Assistant professor, \\ Anna University, Chennai \\ Dhanalakshmi College \\ Engineering, Chennai.
}

\author{
S.Manigandan, M.E \\ Assistant professor \\ Anna University, Chennai, \\ Dhanalakshmi College \\ Engineering, Chennai.
}

\begin{abstract}
High power factor, high frequency single stage single switch resonant inverter for the application of high frequency applications is presented in this paper. The power circuit is designed with a power factor corrector with single-switch current-fed high frequency resonant inverter. Number of switches used in conventional ballast circuits is reduced in single switch approach. SEPIC (Single ended primary inductor converter) is operated in DCM (discontinuous conduction mode) and the drawbacks of conventional class $\mathrm{E}$ resonant are overcome. The problem of gate circuit design of switches and isolation are greatly reduced due to the usage of single switch. The presence of input filters makes the input current ripple free. The simulation results of single switch High Frequency Resonant Inverter for CFL Applications circuit for high frequency of $80 \mathrm{kHz}$ have been presented.
\end{abstract}

\section{Keywords}

Electronic ballast, Power Factor Corrector (PFC), Resonant Inverter, Single Ended Primary Inductor Converter (SEPIC), Compact fluorescent lamps (CFL).

\section{INTRODUCTION}

With increased world's depleting energy resources, power electronics is now playing a key role in providing improved energy-saving technology in lightning field to save energy; gradually conventional incandescent lamps are replaced with compact fluorescent lamps (CFL).

Compact fluorescent lamp belongs to the category of lowpressure discharge lamps. The discharge lamps generate two main lines at $185 \mathrm{~nm}$ and $253.7 \mathrm{~nm}$ and other weak lines in the visible range. A CFL power on the inside wall of the discharge tube converts $\mathrm{u}-\mathrm{v}$ radiations into visible radiation. Usually electromagnetic ballast is commonly used to stabilize the lamp at the required operating point by limiting the discharge current.

The electronic ballast has following drawbacks:1. Low efficiency, especially for that ballast featuring good lamp power regulation against line voltage variation, 2. Difficulty in controlling the lamp luminous flux (dimming), 3. Lamp operating point changes due to the lamp aging process that reduces lamp life, 4. Low input power factor and high harmonic distortion

A conventional high power factor electronic ballast circuit consists of a boost front-end converter to perform power factor correction (PFC) and a half-bridge voltage fed resonant inverter to control the lamp current. Although this approach can achieve high power factor at the input and ensure a low lamp crest factor (CF) at the output, it requires three MOSFETs in the power circuit and two controllers in the overall system. The resulting circuit is costly and too large to be practical in CFL applications. Hence, the two-stage approach lowers the power conversion efficiency.

Conventional CFL electronic ballast, however, consists of a large DC link capacitor placed in front of a half bridge resonant inverter. Hence various single-stage resonant inverters have been introduced by combining both the active PFC stage and the resonant inverter stage. This paper proposes a new single stage single switch electronic ballast that can achieve unity power factor for CFL applications. Since only one MOSFET is required in the proposed circuit, the conduction loss of the overall circuit is reduced. High power factor is achieved in the proposed circuit compared to existing method.

Normally, the output voltage has to be as high as twice the peak line voltage, producing a considerably high voltage stress across the switches. Disadvantage of this existing ballast circuit when operated in DCM and open loop are [1]. , A compact lamp power circuit is designed by integrating a buck-boost power factor corrector with a current-fed resonant inverter. This integration produces a single power-processing unit that minimizes the number of circuit components [3]. The self-oscillating electronic ballast is represented as a relay control system in order to determine its parameters using the describing-function method and an extended Nyquist stability criterion [9].

\section{SINGLE STAGE HIGH FREQUENCY LC RESONANT INVERTER}

The paper was proposed to design a low-cost and small-size high-power-factor electronic ballast circuit for CFLs application. The design objective is to reduce the number of active components (i.e., diode and MOSFET) in the power circuit. Since it is not possible to further reduce the switch count from the active PFC stage perspective, switch count reduction is performed on the inverter stage. A single switch current-fed resonant inverter is proposed by connecting the switch $\left(\mathrm{M}_{1}\right)$ in series with a diode $\left(\mathrm{D}_{1}\right)$. The other circuit elements that make up the single switch inverter include: an input inductor $\left(\mathrm{L}_{\mathrm{in}}\right)$ and a resonant circuit consists of $\mathrm{L}_{\mathrm{r}}$ and $\mathrm{C}_{\mathrm{r}}$, and a starting inductor. The conduction loss of the MOSFET is significantly reduced in the single switch ballast circuit compared to the class-E resonant inverter. Another advantage of the proposed single switch resonant inverter is that the MOSFET voltage stress is much lower than that of the class-E resonant inverter. The MOSFET peak voltage of a class-E resonant inverter is approximately 3-5 times the peak of the input voltage. However, in the proposed circuit, the voltage across the MOSFET is a function of both $\mathrm{L}_{\text {in }}$ and $\mathrm{C}_{\mathrm{r}}$. Hence, by properly designing $\mathrm{L}_{\mathrm{in}}$ and $\mathrm{C}_{\mathrm{r}}$, the voltage across the MOSFET can be minimized. DC-DC converters such as 
the boost, buck-boost, fly back, Cuk, and SEPIC are all possible options for active PFC. In the proposed design, the SEPIC converter is chosen for PFC for the following reasons :

1) It does not require a large-size high-voltage dc-link capacitor, as in the boost PFC case.

2) Unlike the discontinuous conduction- mode (DCM) operating boost converter, the dc-link capacitor of the SEPIC converter does not suffer from high voltage stress in order to achieve high power factor

3) The output dc-link voltage polarity is not inverted, as in the buck-boost converter case, which allows simpler circuit configuration and input electromagnetic interference (EMI) filter designs. Single switch high frequency resonant inverter is shown in Fig 1.

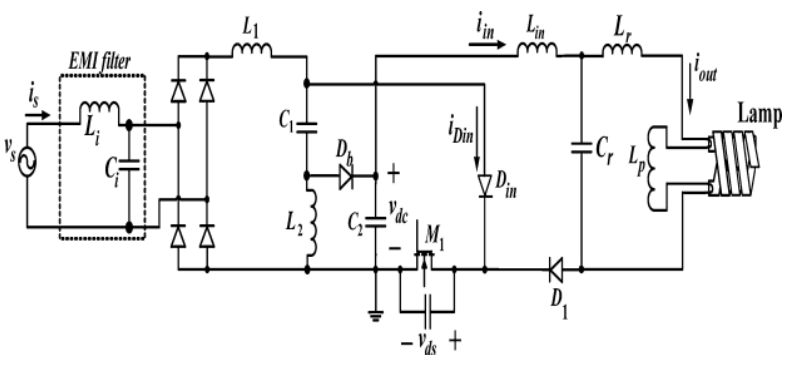

Fig1. Single switch electronic ballast circuit

When the SEPIC converter operates in DCM with a fixed switching frequency, the peak of the DCM inductor current will follow the rectified sinusoidal envelope and a close to- unity power factor is achieved at the input. This feature can be analysed by first examining the input line voltage. The input line voltage is given by: $v_{s}(t)=V_{p}$ $\sin \left(2 \pi f_{L} t\right)$, where $V_{p}$ is the peak line voltage and $f_{L}$ is the line frequency and $t$ is the switching period. From (1), it can be observed that is $\operatorname{avg}(t)$ is purely sinusoidal and is in phase width $\mathrm{v}_{\mathrm{s}}(\mathrm{t})$. Therefore, a very high power factor is achieved at the input. Another advantage of the SEPIC converter is that the input line current ripple can be reduced by properly designing the two inductors $\left(\mathrm{L}_{1}\right.$ and $\left.\mathrm{L}_{2}\right)$ and capacitor $\mathrm{C}_{1}$. By doing so, an input LC filter can be saved in the SEPIC PFC configuration. As a result, it can be concluded that SEPIC converter is capable of achieving all the advantages of the other DC-DC converters for PFC application.

\subsection{Working of input filter of single switch electronic ballast}

Capacitors inhibit direct current, in which a significant amount of electromagnetic interference is carried into a device, while permitting alternating current to pass. Inductors are essentially tiny electromagnets that are able to hold energy in a magnetic field as electric current is passed through it, thereby reducing total voltage. The capacitors used in EMI filters are called shunting capacitors, which redirect current in a specific range, high frequency, away from a circuit or component. The shunting capacitor feeds the high frequency current interference into inductors that are arranged in series. As the current passes through each inductor, the overall strength or voltage is reduced. Optimally, the inductors will reduce the interference to nothing, also called shorting to ground.

\subsection{Mode 1 operation}

In mode 1 the MOSFET switch is $\mathrm{ON}$ and the inductor current $\mathrm{i}_{\mathrm{L}}$ rises linearly, $\mathrm{i}_{\mathrm{in}}$ increases slowly due to the presence of $\mathrm{L}_{\text {in }}$, hence MOSFET switch is turned $\mathrm{ON}$ at close to zero-current switching the total current flowing through the MOSFET is the sum of $I_{\text {in }}$ and $I_{\text {din }}$ which is shown in fig2. Mode 1 ends with when $i_{L}$ reaches maximum value and MOSFET turns OFF

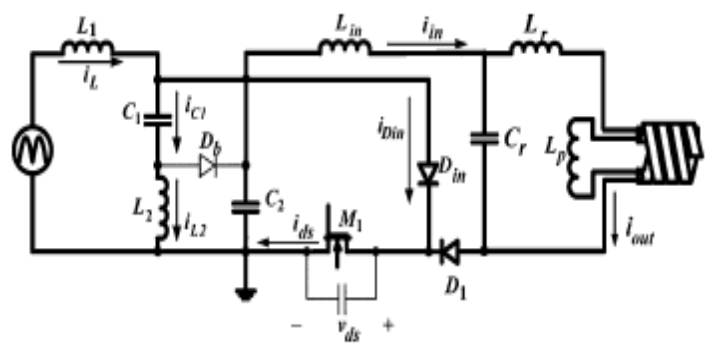

Fig2. Mode1 operation

\subsection{Mode 2 operation}

Mode 2 starts when MOSFET turns OFF $i_{L}$ starts decreasing linearly through diode $\mathrm{D}_{\mathrm{b}}$ until it equals to $\mathrm{i}_{\mathrm{L} 2}$. This mode ends when diode stops conducting and mode 2 equivalent circuit is shown in fig 3 .

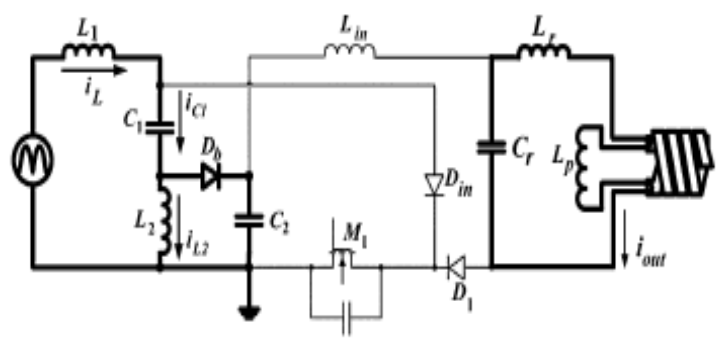

Fig3. Mode2 operation

\subsection{Mode 3 operation}

All three diodes are OFF with the resonant circuit continuing to deliver the required energy to the output. Now, $\mathrm{i}_{\mathrm{L}}$ flows through both $\mathrm{L}_{1}$ and $\mathrm{L}_{2}$. After this stage, the next switching cycle starts again. Mode 3 operation is shown in fig. 4.

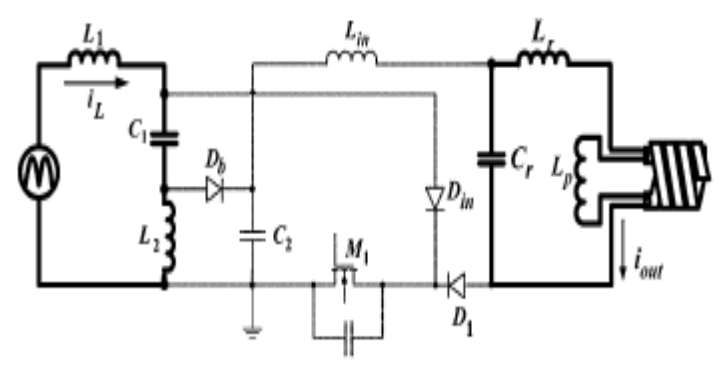

Fig4. Mode 3 operation

\section{SIMULATION RESULTS}

\subsection{Open loop without disturbance}

The simulation model of single switch resonant inverter is shown in Fig 5.The simulation has been done by considering commercial 13-W CFL and simulation waveforms have been given. 


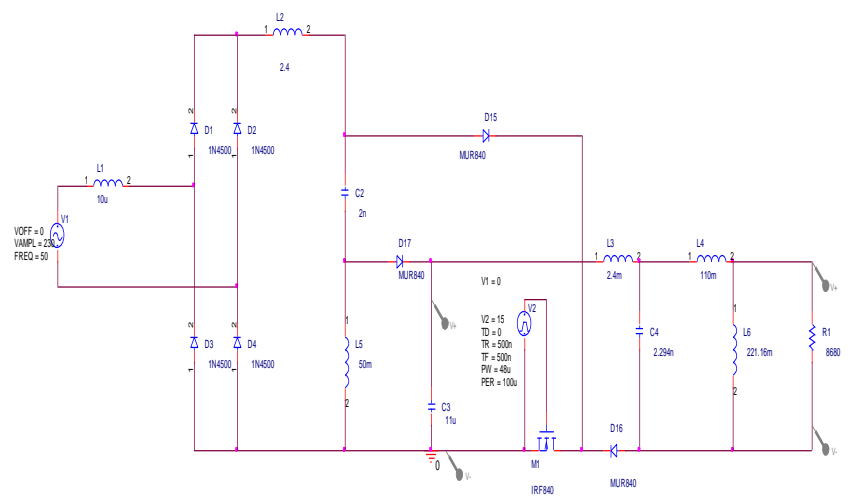

Fig5. Open loop without disturbance

\subsection{Open loop with disturbance}

The simulation model of single switch resonant inverter with input disturbance is shown in Fig 6 The input capacitive filter values have changed from $15 \mathrm{nF}$ to $50 \mathrm{nF}$ for filtering purpose. The disturbance is added in series to the source in the circuit of single switch electronic ballast.

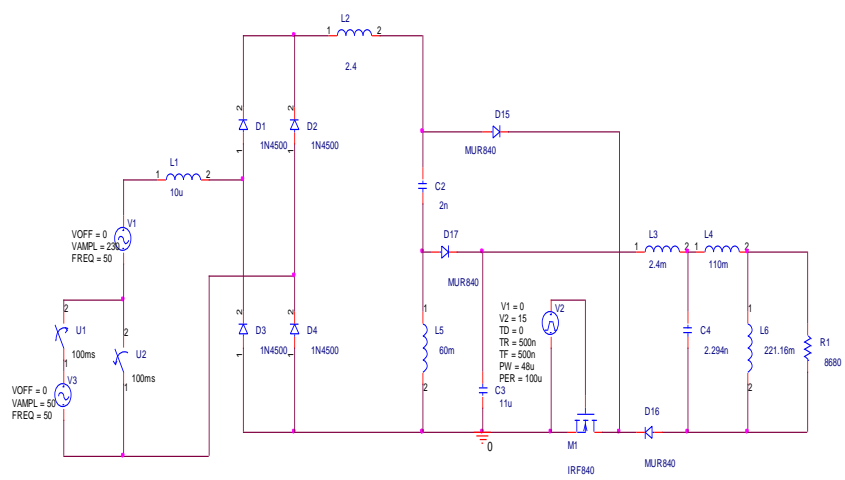

Fig6. Open loop with disturbance

\subsection{Input Disturbance Waveform}

The step input of $30 \mathrm{~V}$ is introduced to the single switch electronic ballast simulation circuit and the output response of the single switch resonant inverter circuit with disturbance is shown in fig 7.

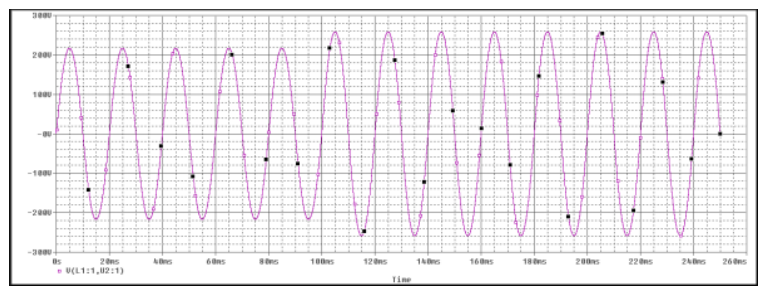

Fig7. Step Input Response

\subsection{Rectified DC Voltage}

The rectified DC voltage waveform is shown in fig 9. The effect of step input is observed after 100ms delay time.

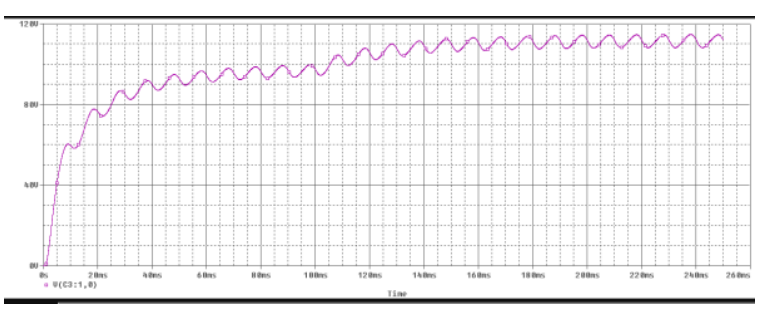

Fig9. Rectified DC Voltage

\subsection{Load voltage}

The output voltage across the lamp load of $15 \mathrm{~W}$ energy saving compact fluorescent lamp is shown in Fig 10. The voltage obtained is around $220 \mathrm{~V}, 80 \mathrm{kHz}$ AC. When the output load voltage is at high frequency the flickering in the lamp is eliminated.

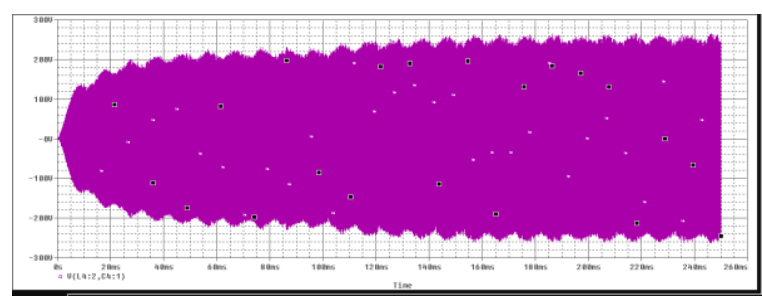

Fig10. Load voltage

\subsection{Load current}

The output load current wave for a $15 \mathrm{~W}$ energy saving compact fluorescent lamp form is shown Fig 11. The amplitude of the lamp load current is about $1.2 \mathrm{~A}$ with the frequency of $80 \mathrm{kHz}$.

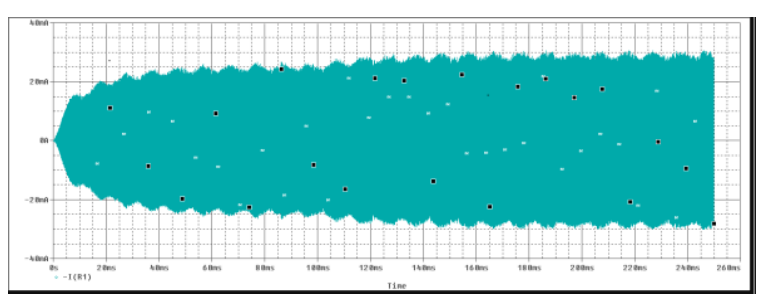

Fig11. Load current

\section{CONCLUSION}

High-power-factor single-switch electronic ballast has been introduced for compact fluorescent lamp applications. Due to its single-switch characteristics, the switching and conduction losses are reduced to great extent and also, both the semiconductor complexity level and the MOSFET driver design are greatly simplified, compared to the existing electronic ballast. The simulation has been carried out in the ORCAD 9.2 lite version and the simulation results shows that the output power factor is close to unity and is achieved at high frequency of $80 \mathrm{kHz}$.

\section{REFERENCES}

[1] Alonso. J. M, Calleja. A. J, Ribas. J, Corominas. E. L, and Rico- Secades. M, (Mar. 2004 ) "Analysis and design of a novel single-stage high-power-factor electronic ballast based on integrated buck half-bridge resonant inverter," IEEE Trans. Power Electron., vol. 19, no. 2, pp. 550-559. 
[2] Deng. E and Cuk. S, "Single switch, unity power factor, lamp ballasts," in Proc. 1995 IEEE Appl. Power Electron. Conf. Expo., pp. 670-676.

[3] Lam. J. C. W and Jain. P. K, (Nov. 2008) "A dimmable electronic ballast with unity power factor based on a single-stage current-fed resonant inverter," IEEE Trans. Power Electron., vol. 23, no. 6, pp. 3103-3115.

[4] Morais. A. S. de, Farias. V. J, L. C. de Freitas,. Coelho E. A. A and J. B. Vieira, Jr., (Mar. 2006) "A high power factor ballast using a single switch with both power stages integrated," IEEE Trans. Power Electron., vol. 21, no. 2 , pp. 524-531.

[5] Melvin c. Cosby, jr. and r. M. Nelms, senior member, IEEE, (august 1994) "A resonant inverter for Electronic ballast applications", IEEE transactions on industrial electronics, vol. 41. no. 4, pp.418-425.

[6] Ponce. M.,Martinez., Correa. A. J., Cotorogea. M, and Arau. J, (Mar. 2006) "High-efficient integrated electronic ballast for compact fluorescent lamps," IEEE Trans. Power Electron., vol. 21, no. 2, pp. 532-542.
[7] Ponce. M., Vazquez RArau. J, and D. Abud, "Class E amplifiers used as a high power factor electronic ballasts for fluorescent lamps in a single stage," in Proc. 1998 Power Electron. Spec. Conf. (PESC), pp. 2009-2015.

[8] Ponce. M, A. L'opez, Correa. J, Arau. J, and J. M. Alonso, "A novel high-power-factor single-switch electronic ballast for compact fluorescent lamps," in Proc. 2001 IEEE Appl. Power Electron. Conf. Expo., pp. 454- 460 .

[9] Seidel. A. R., Bisogno. F. E. and R. N. do Prado, (Nov./Dec. 2007) "A design methodology for a selfoscillating electronic ballast," IEEE Trans. Ind. Appl., vol. 43, no. 6, pp. 1524-1533.

[10] Seidel. A. R, Bisogno. F. E. Marchesan. T. B, and R.N. do Prado, "Designing a self-oscillating electronic ballast with bipolar transistor," in Proc.2002 Ind. Appl. Conf., pp. 1078-1083. 